\title{
Modern Clinical and Epidemiological Features and New Technological Possibilities in the Treatment of Bleeding Gastroduodenal Ulcers
}

\author{
Sergey V. Barannikov, $\mathrm{PhD}^{1}$; Evgeniy F. Cherednikov, $\mathrm{PhD}, \mathrm{ScD}^{1}$; Igor S. Yuzefovich', $\mathrm{PhD}$; \\ Igor N. Banin ${ }^{1,2}, \mathrm{PhD}$; Galina V. Polubkova, $\mathrm{PhD}^{1}$; Anastasiya T. Vysotskaya ${ }^{1}, \mathrm{PhD}$; \\ Yuri V. Maleev, $\mathrm{PhD}, \mathrm{ScD}^{3}$; Evgeniy S. Ovsyannikov, $\mathrm{PhD}, \mathrm{ScD}^{1}$; \\ Aleksandr V. Chernykh ${ }^{1}, \mathrm{PhD}, \mathrm{ScD}$ \\ ${ }^{1}$ Voronezh State Medical University named after N. N. Burdenko \\ ${ }^{2}$ Voronezh City Clinical Emergency Hospital \#1 \\ ${ }^{3}$ Voronezh Basic Medical College \\ Voronezh, the Russian Federation
}

\begin{abstract}
The aim of this research was to study the current clinical and epidemiological features of ulcerative gastroduodenal bleeding (GDB) and to evaluate the outcomes of using new technological approaches in patients with bleeding from acute (symptomatic) and chronic (peptic ulcer disease) gastroduodenal ulcers.

Methods and Results: The present study involved 221 patients with bleeding gastroduodenal ulcers. Depending on the source of bleeding, all patients were divided into 2 groups. Group 1 included 143 patients with acute symptomatic gastroduodenal ulcers; Group 2 consisted of 78 patients with peptic ulcer disease (PUD) complicated by bleeding. In the complex treatment of patients of all the studied groups, an individual approach was used that included the innovative technologies of endoscopic cytoprotective treatment of GDB, based on the combined use of traditional means of endoscopic hemostasis (EH) in combination with the use of endoscopic pneumoinsufflation of biologically active drainage sorbent of a new generation Aseptisorb-D and powdered hemostatic Zhelplastan. Our analysis showed that acute symptomatic gastroduodenal ulcers prevailed in the structure of GDB - 143(64.7\%) patients; PUD complicated by bleeding was diagnosed in 78(35.3\%) cases. To assess the type of ulcerative bleeding, the classification of J. Forrest (1974) was used. The use of new technological approaches, including cytoprotective treatment of bleeding defects with biologically active draining sorbents of a new generation in combination with local hemostatics in the complex therapy of patients with ulcerative GDB, has significantly improved the results of treatment, which is confirmed by high rates of final hemostasis $(95.0 \%)$, indicators of the effectiveness of primary EH in type FIA-IB (93.1\%) and prevention of recurrence of FIIA-IIB bleeding $(92.5 \%)$, with a low frequency of repeated bleeding $(4.07 \%)$, emergency surgeries $(2.7 \%)$, and mortality $(3.2 \%)$.

Conclusion: Currently, in the structure of ulcerative GDB, acute symptomatic gastroduodenal ulcers are the most common - 64.7\%, and the share of PUD complicated by bleeding accounts for $35.3 \%$ of cases only. PUD and gastroduodenal ulcers complicated by bleeding have certain clinical and epidemiological features, which must be taken into account when treating these patients. Symptomatic gastroduodenal ulcers are more difficult to treat, which shows the need to develop new complex technologies for their treatment.(International Journal of Biomedicine. 2021;11(4):428-434.)
\end{abstract}

Key Words: bleeding gastroduodenal ulcers $\bullet$ endoscopic hemostasis $\bullet$ biologically active drainage sorbent

For citation: Barannikov SV, Cherednikov EF, Yuzefovich IS, Banin IN, Polubkova GV, Vysotskaya AT, Maleev YuV, Ovsyannikov ES, Chernykh AV. Modern Clinical and Epidemiological Features and New Technological Possibilities in the Treatment of Bleeding Gastroduodenal Ulcers. International Journal of Biomedicine. 2021;11(4):428-434. doi:10.21103/Article11(4)_OA6

\section{Abbreviations}

APC, argon-plasma coagulation; EH, endoscopic hemostasis; GDB, gastroduodenal bleeding; GDUs, gastroduodenal ulcers; PUD, peptic ulcer disease. 


\section{Introduction}

The problem of treating patients with bleeding gastroduodenal ulcers (GDUs) is among the most difficult in modern urgent surgery. High mortality rates indicate an urgent need to improve modern technologies for the treatment of this pathology. ${ }^{(1-6)}$

The etiological structure of GDUs, according to many studies, has undergone significant changes in recent decades. If in the 1990s, in the structure of GDB, the share of complicated peptic ulcer disease (PUD) of the stomach and duodenum accounted for up to $70.2 \%$ of cases, currently, their number does not exceed $30.6 \%$. At the same time, however, acute symptomatic GDUs are becoming increasingly important in clinical practice (7-10) $^{(7)}$

The treatment of patients with acute bleeding GDUs is a difficult task of modern gastric surgery. These patients often have severe co-morbid pathology, multiple lesions of the mucoussubmucosal layer of the digestive tract, disorders of platelet and coagulation links of hemostasis against the background of taking antiplatelet drugs, anticoagulants, and other drugs..$^{(11-15)}$

Minimally invasive hemostasis technologies are becoming increasingly important in the treatment of patients with acute symptomatic GDUs. Various methods of endoscopic hemostasis (EH) have become widespread: argon-plasma coagulation (APC), laser coagulation, diathermocoagulation, injection hemostasis, clipping and combined techniques. But even when using combined methods of traditional endohemostasis, the frequency of recurrent bleeding reaches $10 \%-46 \%$, which shows the need to use new technological capabilities in treating patients with ulcerative GDB. (16-20) $^{-}$

The aim of this research was to study the current clinical and epidemiological features of ulcerative GDB and to evaluate the outcomes of using new technological approaches in patients with bleeding from acute (symptomatic) and chronic (PUD) GDUs.

\section{Materials and Methods}

A clinical study was conducted in the Voronezh City Specialized Center for the treatment of patients with gastrointestinal bleeding (Voronezh City Clinical Emergency Hospital №1) in 202-2021. The present study involved 221 patients with bleeding GDUs. Depending on the source of bleeding, all patients were divided into 2 groups. Group 1 included 143 patients with acute symptomatic GDUs; Group 2 consisted of 78 patients with PUD complicated by bleeding.

The clinical and epidemiological characteristics of the study groups are presented in Table 1 .

Our analysis showed that acute symptomatic GDUs prevailed in the structure of GDB -143(64.7\%) patients; PUD complicated by bleeding was diagnosed in 78(35.3\%) cases. The structure of the general incidence of bleeding GDUs was dominated by persons of retirement age $-53.0 \%$ of patients. At the same time, the retirement age was typical for Group $1(66.6 \%)$. However, there was an opposite picture among patients of Group 2: $71.7 \%$ of patients were of working age, and only $28.3 \%$ of retirement age.
Table 1.

Clinical and epidemiological characteristics of the study groups

\begin{tabular}{|c|c|c|c|c|}
\hline Indicator & $\begin{array}{l}\text { Group 1 } \\
(\mathrm{n}=143)\end{array}$ & $\begin{array}{c}\text { Group } 2 \\
(\mathrm{n}=78)\end{array}$ & $P$-value & $\begin{array}{c}\text { General } \\
\text { group } \\
(\mathrm{n}=221)\end{array}$ \\
\hline \multicolumn{5}{|c|}{ Social status of patients } \\
\hline Employee & $20(13.9 \%)$ & $24(30.7 \%)$ & $\mathrm{P}=0.0028$ & $44(19.9 \%)$ \\
\hline Non-employee & $28(19.5 \%)$ & $32(41.0 \%)$ & $\mathrm{P}=0.0006$ & $60(27.1 \%)$ \\
\hline Pensioner & $95(66.6 \%)$ & $22(28.3 \%)$ & $\mathrm{P}=0.0000$ & $117(53.0 \%)$ \\
\hline \multicolumn{5}{|c|}{ Age and gender of patients } \\
\hline Age (years) & $\begin{array}{c}69.0 \\
(54.0 ; 79.0)\end{array}$ & $\begin{array}{c}51.0 \\
(37.0 ; 61.0)\end{array}$ & $\mathrm{P}<0.001$ & $\begin{array}{c}62.0 \\
(47.0 ; 72.0)\end{array}$ \\
\hline Men & $84(58.7 \%)$ & $61(78.2 \%)$ & $\mathrm{P}=0.0036$ & $145(65.6 \%)$ \\
\hline Women & $59(41.3 \%)$ & $17(21.8 \%)$ & $\mathrm{P}=0.0036$ & $76(34,4 \%)$ \\
\hline \multicolumn{5}{|c|}{ Localization of the source of bleeding } \\
\hline $\begin{array}{l}\text { Duodenal } \\
\text { ulcers }\end{array}$ & $72(50.3 \%)$ & $55(70.5 \%)$ & $\mathrm{P}=0.0038$ & $127(57.5 \%)$ \\
\hline $\begin{array}{l}\text { Stomach } \\
\text { ulcers }\end{array}$ & $71(49.7 \%)$ & $12(15.3 \%)$ & $\mathrm{P}=0.0000$ & $83(37.5 \%)$ \\
\hline \begin{tabular}{|l|} 
Gastroentero- \\
anastomosis- \\
ulcers
\end{tabular} & - & $11(14.2 \%)$ & - & $11(5.0 \%)$ \\
\hline \multicolumn{5}{|c|}{ Number of gastroduodenal ulcers } \\
\hline One & $119(83.2 \%)$ & $71(91.0 \%)$ & $\mathrm{P}=0.1102$ & $190(85.9 \%)$ \\
\hline Two & $12(8.4 \%)$ & $7(9.0 \%)$ & $\mathrm{P}=0.8821$ & $19(8.6 \%)$ \\
\hline Multiple & $12(8.4 \%)$ & - & - & $12(5.5 \%)$ \\
\hline \multicolumn{5}{|c|}{ Localization of stomach ulcers } \\
\hline $\begin{array}{l}\text { Body of the } \\
\text { stomach }\end{array}$ & $43(60.5 \%)$ & $6(50.0 \%)$ & $\mathrm{P}=0.0001$ & $49(59.0 \%)$ \\
\hline Antrum & $22(30.9 \%)$ & $5(41.6 \%)$ & $\mathrm{P}=0.0516$ & $27(32.5 \%)$ \\
\hline $\begin{array}{l}\text { Cardiac and } \\
\text { fundus of } \\
\text { the stomach }\end{array}$ & $4(8.6 \%)$ & $1(8.4 \%)$ & $\mathrm{P}=0.6587$ & $5(8.5 \%)$ \\
\hline \multicolumn{5}{|c|}{ Localization of duodenal ulcers } \\
\hline Anterior wall & $29(40.2 \%)$ & $24(43.6 \%)$ & $\mathrm{P}=0.0809$ & $53(41.7 \%)$ \\
\hline Posterior wall & $12(16.6 \%)$ & $5(9.0 \%)$ & $\mathrm{P}=0.5974$ & $17(13.4 \%)$ \\
\hline Upper wall & $24(33.3 \%)$ & $20(36.3 \%)$ & $\mathrm{P}=0.1151$ & $44(34.6 \%)$ \\
\hline Lower wall & $8(9.9 \%)$ & $6(11.1 \%)$ & $\mathrm{P}=0.7471$ & $14(10.3 \%)$ \\
\hline \multicolumn{5}{|c|}{ Bleeding type (21) } \\
\hline Forrest IA & $15(10.4 \%)$ & $2(2.5 \%)$ & $\mathrm{P}=0.0346$ & $17(7.7 \%)$ \\
\hline Forrest IB & $9(6.2 \%)$ & $3(3.8 \%)$ & $\mathrm{P}=0.4428$ & $12(5.4 \%)$ \\
\hline Forrest IIA & $11(7.6 \%)$ & $8(10.2 \%)$ & $\mathrm{P}=0.5159$ & $19(8.6 \%)$ \\
\hline Forrest IIB & $34(23.7 \%)$ & $14(17.9 \%)$ & $\mathrm{P}=0.3154$ & $48(21.7 \%)$ \\
\hline Forrest IIC & $64(44.7 \%)$ & $40(51.2 \%)$ & $\mathrm{P}=0.3529$ & $104(47.1 \%)$ \\
\hline Forrest III & $10(7.4 \%)$ & $11(14.4 \%)$ & $\mathrm{P}=0.0850$ & $22(9.5 \%)$ \\
\hline
\end{tabular}


Table 1.

Clinical and epidemiological characteristics of the study groups (continued)

\begin{tabular}{|c|c|c|c|c|}
\hline & $\begin{array}{l}\text { Group } 1 \\
(\mathrm{n}=143)\end{array}$ & $\begin{array}{c}\text { Group } 2 \\
(\mathrm{n}=78)\end{array}$ & $P$-value & $\begin{array}{l}\text { General } \\
\text { group } \\
(\mathrm{n}=221)\end{array}$ \\
\hline \multicolumn{5}{|c|}{ The degree of severity of blood loss ${ }^{(22)}$} \\
\hline Mild & $68(47.5 \%)$ & $44(56.4 \%)$ & \multirow{3}{*}{$\mathrm{P}=0.4444$} & $112(50.7 \%)$ \\
\hline Moderate & $25(17.5 \%)$ & $12(15.4 \%)$ & & $37(16.7 \%)$ \\
\hline Severe & $50(35.0 \%)$ & $22(28.2 \%)$ & & $72(32.6 \%)$ \\
\hline \multicolumn{5}{|c|}{ Helicobacter pylori test results } \\
\hline Positive & $16(11.1 \%)$ & $32(41.0 \%)$ & \multirow{2}{*}{$\mathrm{P}=0.0000$} & $48(21.7 \%)$ \\
\hline Negative & $127(88.9 \%)$ & $46(59.0 \%)$ & & $173(78.3 \%)$ \\
\hline
\end{tabular}

The average age of patients of Group 2 was $51.0(37.0 ; 61.0)$ years, while in Group 1, the average age was significantly higher - 69.0(54.0;79.0) years $(P<0.001)$..

The gender composition of patients was as follows: $78.2 \%$ men and $21.8 \%$ women in Group 2, 58.7\% men and 41.3\% women in Group 1.

Depending on the location of the source of bleeding, patients with bleeding GDUs were distributed as follows: bleeding ulcers of the duodenum $-57.5 \%$, stomach ulcers and gastroenteroanastomosis $-37.5 \%$ and $5.0 \%$, respectively. In Group 1, duodenal ulcers accounted for $50.3 \%$ of cases, and stomach ulcers for $49.7 \%$. In Group 2, duodenal ulcers accounted for $70.5 \%$ of cases, stomach ulcers for $15.3 \%$, and gastroenteroanastomosis ulcers for $14.2 \%$. It should be noted that GDUs in $85.9 \%$ of cases were single; paired and multiple GDUs were found in $8.6 \%$ and $5.5 \%$ of cases, respectively.

When analyzing the localization of ulcerative defects, we found that for stomach ulcers, the most typical localization was the stomach body $-59.0 \%$ of cases; the antrum of the stomach $-32.5 \%$; ulcers of the cardiac region and the fundus of the stomach were less common $-8.5 \%$ of cases. For duodenal ulcers, damage to the anterior and upper walls of the duodenum was the most frequent $(41.7 \%$ and $34.6 \%$, respectively), damage to the posterior and lower walls was less frequent (13.4\% and $10.3 \%$, respectively).

To assess the type of ulcerative bleeding, the classification of J. Forrest was used. ${ }^{(21)}$ The most frequent type of ulcerative bleeding was FIIC $-47.1 \%$ of cases. FIIB type was detected in $21.7 \%$ of patients, FIII in $9.5 \%$, FIIA in $8.6 \%$, FIA in $7.7 \%$, and FIB was observed in only $5.4 \%$ of cases. It should be noted that in patients of Group 1, the type of bleeding FIA was statistically significantly more common than in patients of Group 2: $10.4 \%$ and $2.5 \%$, respectively $(P=0.0346)$.

According to the severity of blood loss, ${ }^{(22)}$ the patients were distributed as follows: the most common were mild and severe degrees of blood loss $-50.7 \%$ and $32.6 \%$ of cases, respectively. A moderate degree of blood loss was observed in $16.7 \%$ of patients. At the same time, there were no statistically significant differences in the volume of blood loss between the study groups.
All patients were examined for the presence of Helicobacter pylori. Positive results of the examination were revealed in $21.7 \%$ of patients; the negative urease test was found in $78.3 \%$ of patients. At the same time, positive test results for Helicobacter pylori were detected in $41.0 \%$ of cases in Group 2 and only in $11.1 \%$ of cases in Group 1 $(P<0.0001)$.

The structure of concomitant pathology in patients with ulcerative GDB is presented in Table 2. In the structure of concomitant pathology in patients with ulcerative hemorrhages, diseases of the cardiovascular system prevailed $(66.0 \%)$. It should be noted that for patients of Group 1, compared with Group 2, diseases of the cardiovascular system were much more common. Also, in patients of Group 1 diabetes mellitus was more common than in Group $2-13.9 \%$ and $3.8 \%$, respectively $(P=0.018)$.

\section{Table 2.}

\section{Structure of concomitant pathology}

\begin{tabular}{|l|c|c|l|l|}
\hline & $\begin{array}{c}\text { Group 1 } \\
(\mathrm{n}=143)\end{array}$ & $\begin{array}{c}\text { Group 2 } \\
(\mathrm{n}=78)\end{array}$ & $P$-value & $\begin{array}{c}\text { General } \\
\text { group } \\
\mathrm{n}=221)\end{array}$ \\
\hline $\begin{array}{l}\text { Diseases of the } \\
\text { cardiovascular system }\end{array}$ & $108(75.5 \%)$ & $38(48.7 \%)$ & $\mathrm{P}=0.0001$ & $146(66.0 \%)$ \\
\hline $\begin{array}{l}\text { Respiratory system } \\
\text { diseases }\end{array}$ & $13(9.1 \%)$ & $7(8.9 \%)$ & $\mathrm{P}=0.9748$ & $20(9.04 \%)$ \\
\hline $\begin{array}{l}\text { Digestive system } \\
\text { diseases }\end{array}$ & $33(20.1 \%)$ & $18(23.1 \%)$ & $\mathrm{P}=0.8671$ & $51(23.1 \%)$ \\
\hline $\begin{array}{l}\text { Diseases of the mus- } \\
\text { culoskeletal system }\end{array}$ & $5(3.5 \%)$ & $1(1.28 \%)$ & $\mathrm{P}=0.4278$ & $6(2.7 \%)$ \\
\hline $\begin{array}{l}\text { Diseases of } \\
\text { the urinary system }\end{array}$ & $21(14.7 \%)$ & $7(8.9 \%)$ & $\mathrm{P}=0.2225$ & $28(12.7 \%)$ \\
\hline $\begin{array}{l}\text { Nervous system } \\
\text { diseases }\end{array}$ & $14(9.8 \%)$ & $5(6.4 \%)$ & $\mathrm{P}=0.3916$ & $19(8.6 \%)$ \\
\hline Oncopathology & $9(6.3 \%)$ & $5(6.4 \%)$ & $\mathrm{P}=0.7989$ & $14(6.3 \%)$ \\
\hline Diabetes mellitus & $20(13.9 \%)$ & $3(3.8 \%)$ & $\mathrm{P}=0.0203$ & $23(10.4 \%)$ \\
\hline \multicolumn{5}{|l|}{$\mathrm{Ulcerative}$ medications } \\
\hline Anticoagulants & $22(15.4 \%)$ & $1(1.28 \%)$ & $\mathrm{P}=0.0013$ & $23(10.4 \%)$ \\
\hline Disaggregants & $30(21.0 \%)$ & $11(14.1 \%)$ & $\mathrm{P}=0.2089$ & $41(18.6 \%)$ \\
\hline NSAIDs & $14(9.8 \%)$ & $4(5.12 \%)$ & $\mathrm{P}=0.3061$ & $18(8.1 \%)$ \\
\hline
\end{tabular}

Analyzing the effect of ulcerative medications on the development of ulcerative bleeding, it was found that $18.6 \%$ of patients, just before the development of the bleeding episode, took disaggregants, $10.4 \%$ of patients anticoagulants and $8.1 \%$ - NSAIDs. It is important to note that anticoagulants were much more often taken by patients in Group 1 - in $15.4 \%$ of cases compared to $1.28 \%$ of cases in Group $2(P=0.001)$.

In the complex treatment of patients of all the studied groups, an individual approach was used that included the innovative technologies of endoscopic cytoprotective 
treatment of GDB, based on the combined use of traditional means of $\mathrm{EH}$ in combination with the use of endoscopic pneumoinsufflation of biologically active drainage sorbent of a new generation Aseptisorb-D and powdered hemostatic Zhelplastan (Patent RF № 2633588). ${ }^{(23)}$

Thus, in patients with ongoing bleeding (FIA-FIB), bleeding was initially stopped by injection of a $5 \%$ solution of $\varepsilon$-aminocaproic acid at the source of bleeding, followed by APC. EH in the group always ended with endoscopic insufflations of powdered Zhelplastan in combination with Aseptisorb-D.

In patients with unstably stopped bleeding FIIA-FIIB, the method of endoscopic prevention of the resumption of hemorrhage was used by conducting APC of the thrombosed vessel with the type of bleeding FIIA; and with the type FIIB, the clot was washed from the ulcerative defect with subsequent coagulation of the source of hemorrhage. In order to increase the reliability of hemostasis and prevent recurrence of bleeding and endoscopic cytoprotective treatment, each case of therapeutic endoscopy always ended with pneumoinsufflation of Zhelplastan in combination with Aspetisorb-D.

In patients with bleeding type FIIC and FIII, endoscopic treatment was performed through combined insufflations of Zhelplastan and Aspetisorb-D in order to accelerate the processes of reparative regeneration and prevent possible resumption of bleeding.

In complex treatment, patients received modern drug therapy according to the standards of treatment of patients with ulcerative bleeding: antisecretory drugs proton pump inhibitors (esomeprazole), general hemostatics with the inclusion of modern hemostatics (tranexamic acid, aminomethylbenzoic acid), infusion-transfusion and symptomatic therapy. The indication for surgical treatment in patients with ulcerative bleeding was continued bleeding with the impossibility or ineffectiveness of $\mathrm{EH}$ and recurrence of hemorrhage in hospital PUD inpatients, according to National Clinical Guidelines for the treatment of patients with ulcerative GDB. ${ }^{(24)}$

The following indicators assessed the effectiveness of the treatment: reliability of primary hemostasis in type FIA-IB, effectiveness of endoscopic prevention of recurrent bleeding in types FIIA-IIB and FIIC, frequency of bleeding recurrence, prevention of emergency operations, mortality rates.

Statistical analysis was performed using Microsoft Excel software package. For descriptive analysis, results are presented as median (Me) and interquartile range $(I Q R)$. Wilcoxon rank sum test was used to test for difference in medians. Group comparisons with respect to categorical variables are performed using chi-square tests with Yates correction or, alternatively, Fisher's exact test when expected cell counts were less than 5. A probability value of $P<0.05$ was considered statistically significant.

The study was carried out in compliance with Ethical Principles for Medical Research Involving Human Subjects, Adopted by the 18th WMA General Assembly, Helsinki, Finland, June 1964, and amended by the 64th WMA General Assembly, Fortaleza, Brazil, October 2013. The study was approved by the Ethics Committee of Voronezh State Medical University named after N. N. Burdenko. Written informed consent was obtained from all participants.

\section{Results and Discussion}

All patients in the studied groups received personalized preventive technologies of cytoprotective treatment of GDUs complicated by bleeding with biologically active granular sorbent of a new generation Aseptisorb-D in combination with the hemostatic agent Zhelplastan, according to the developed technique. Studies have shown that immediately after pneumoinsuflation, Aseptisorb-D in combination with Zhelplastan formed a powerful layer of biologically active hydrogel on ulcerative defects, which protected the ulcerative defect, thrombosed vessel, and coagulation necrosis from the aggressive action of gastric and duodenal contents, showing local hemostatic and cytoprotective effects, preventing the resumption of bleeding and contributing to the favorable course of the reparative process in ulcerative defects.

At the same time, it was noted that in 24 patients of Group 1 with the FIA-FIB type of bleeding, primary EH was achieved in 23(95.8\%) patients.

Clinical example. In a 47-year-old woman, against the background of uncontrolled Warfarin intake, continued bleeding from an acute ulcer of the duodenum was not stopped endoscopically. This patient was urgently operated on - a bleeding vessel in the ulcer was stitched. The postoperative period proceeded without complications, the patient was discharged for outpatient treatment on Day 13 after inpatient treatment

There were no episodes of resumption of bleeding after successful primary EH in Group 1. In this group of patients, a 66-year-old man with the FIA type of bleeding died: His ongoing bleeding was stopped successfully and no repeated bleeding was noted during inpatient treatment, but the patient died from decompensation of concomitant pathology against the background of acute blood loss.

In Group 2, out of 5 patients with ongoing bleeding (FIA-FIB), primary EH was effective in 4 patients $(80 \%)$. One patient was operated on "at the height of bleeding." There were no relapses of bleeding or fatal outcomes in this group.

When analyzing the results of treatment of patients in Group 1 with unstable stopped bleeding (FIA-FIB), 3(6.67\%) of 45 patients had repeated bleeding. All of these 3 patients had disorders of the blood coagulation system due to taking anticoagulants. In 2 patients, repeated bleeding was stopped endoscopically using the developed techniques in combination with complex hemostatic therapy, which made it possible to avoid surgical treatment. One patient was operated on due to the failure of repeated hemostasis and died of pneumonia in the postoperative period. Also in this group of patients, 2 more, aged 81 and 84, died from decompensation of concomitant diseases on the background of anemia.

In Group 2, hemorrhagic relapses were observed in $2(9.1 \%)$ of 22 patients with unstably stopped bleeding (FIAFIB). Both patients were operated on; they underwent the 
operation "stitching a bleeding vessel" in an ulcer. One patient died in the postoperative period.

In 64 patients of Group 1 with the FIIC type of bleeding, repeated bleeding was observed in $2(3.1 \%)$ patients. These patients also took disaggregants and anticoagulants. All of them underwent repeated $\mathrm{EH}$, according to the developed technique, which was effective in both patients. There were no surgical interventions in this group, but one, a 40-yearold patient, died from decompensation of cardiovascular pathology on the background of anemia.

Of the 40 patients in Group 2 with the FIIC type of bleeding, repeated bleeding was observed in $2(5.0 \%)$ patients. One recurrent bleeding was stopped endoscopically, the second underwent surgical treatment - resection of the stomach. There were no fatal outcomes in this group of patients.

With type FIII bleeding in both groups of patients, there was no recurrence of bleeding, emergency operations, or deaths.

Considering the results of treatment of patients in Group 1 , it should be noted that the resumption of bleeding from acute GDUs in all 5 patients occurred on 1.5(1.0;2.0) days, which was caused primarily by pronounced hypocoagulation on the basis of taking medications. All these patients underwent repeated EH. In $4(80.0 \%)$ out of 5 patients with repeated GDB, the use of the developed innovative technologies of EH made it possible to carry out final hemostasis and avoid surgery; in 1 patient with an acute ulcer of the posterior wall of the duodenum, repeated bleeding could not be stopped endoscopically, and the patient was operated on.

Summarizing the treatment of Group 1 patients with acute GDUs, we noted that in order to achieve final hemostasis in these patients, repeated therapeutic endoscopies, a large number of therapeutic manipulations are necessary, which reduces the effectiveness of the treatment and worsens the quality of life of patients. It is important to note that the cause of acute erosive and ulcerative GDB in most of these patients was taking antiplatelet drugs, which caused them to have disorders of the blood clotting system. The difficulty for the doctor was that most of the patients in this group had a high and very high risk of thromboembolic complications and needed to resume anticoagulant therapy after bleeding was stopped. The decision on the timing of the resumption of therapy with antiplatelet drugs was decided individually, taking into account the risk-benefit ratio in each case.

In addition, of the patients of Group 1 with acute symptomatic GDUs, 66.6\% were of retirement age with severe concomitant pathology. The developing GDB in these patients led to decompensation of somatic pathology, which, along with the bleeding itself, posed a direct threat to the life and health of patients. In treating such patients, it is necessary to maximize all the possibilities of conservative therapy aimed at preventing the resumption of GDB and correcting decompensated somatic pathology.

In treating patients with acute GDB and decompensated concomitant pathology, we also used a multidisciplinary approach. All these patients were hospitalized in the intensive care unit, where a dynamic resuscitator constantly monitored them. In addition, a team of doctors of various specialties was immediately involved in their treatment: therapists, cardiologists, neurologists, pulmonologists, clinical pharmacologists, etc. This approach allowed us to stabilize the condition of patients. However, despite the efforts made, 6(4.19\%) patients of Group 1 died from decompensation of the underlying disease against the background of anemia.

In patients of Group 2 with gastric ulcer and duodenal ulcer, recurrence of ulcerative bleeding was observed on Day $4.0(2.5 ; 6.0)$ of inpatient treatment. The cause of bleeding recurrence in 1 patient was an ulcer of the posterior wall of the duodenum penetrating into the head of the pancreas, and in 3 patients, the development of bleeding recurrence was due to the presence of erosive vessels in the ulcerative defect. All these patients were operated on "at the height of bleeding"; 1 patient died in the postoperative period.

The final results of the treatment of patients are presented in Table 3.

Table 3.

Comparative effectiveness of patient treatment

\begin{tabular}{|l|c|c|l|l|}
\hline & $\begin{array}{l}\text { Group 1 } \\
\text { (n=143) }\end{array}$ & $\begin{array}{l}\text { Group 2 } \\
\text { (n=78) }\end{array}$ & $P$-value & $\begin{array}{l}\text { General } \\
\text { group } \\
\text { (n=221) }\end{array}$ \\
\hline $\begin{array}{l}\text { The effectiveness } \\
\text { of primary EH } \\
\text { in FIA-IB }\end{array}$ & $\begin{array}{c}23(95.8 \% \\
\text { with respect } \\
\text { to } \mathrm{n}=24)\end{array}$ & $\begin{array}{c}4(80 \% \\
\text { with respect } \\
\text { to } \mathrm{n}=5)\end{array}$ & $\mathrm{P}=0.3202$ & $\begin{array}{l}27(93.1 \% \\
\text { with respect } \\
\text { to } \mathrm{n}=29)\end{array}$ \\
\hline $\begin{array}{l}\text { The effectiveness } \\
\text { of endoscopic } \\
\text { prevention of } \\
\text { recurrent bleeding } \\
\text { in FIIA-IIB }\end{array}$ & $\begin{array}{c}42(93.3 \% \\
\text { with respect } \\
\text { to } \mathrm{n}=45)\end{array}$ & $\begin{array}{c}\text { with respect } \\
\text { to } \mathrm{n}=22)\end{array}$ & $\mathrm{P}=0.9999$ & $\begin{array}{c}\text { with respect } \\
\text { to } \mathrm{n}=67)\end{array}$ \\
\hline $\begin{array}{l}\text { Overall } \\
\text { re-bleeding rate }\end{array}$ & $5(3.49 \%)$ & $4(5.1 \%)$ & $\mathrm{P}=0.7235$ & $9(4.07 \%)$ \\
\hline $\begin{array}{l}\text { Day of appearance } \\
\text { of repeated bleeding }\end{array}$ & $1.5(1.0 ; 2.0)$ & $4.0(2.5 ; 6.0)$ & $\mathrm{P}=0.048$ & $2, .(1.5 ; 5.5)$ \\
\hline Final hemostasis & $137(95.8 \%)$ & $73(93.5 \%)$ & $\mathrm{P}=0.5242$ & $210(95.0 \%)$ \\
\hline $\begin{array}{l}\text { Emergency } \\
\text { surgeries }\end{array}$ & $2(1.4 \%)$ & $4(5.12 \%)$ & $\mathrm{P}=0.1882$ & $6(2.7 \%)$ \\
\hline $\begin{array}{l}\text { Suturing a bleeding } \\
\text { vessel in an ulcer }\end{array}$ & $2(1.4 \%)$ & $3(3.8 \%)$ & $\mathrm{P}=0.3482$ & $5(2.3 \%)$ \\
\hline Stomach resection & - & $1(25.0 \%)$ & - & $1(16.7 \%)$ \\
\hline Mortality & $6(4.19 \%)$ & $1(1.3 \%)$ & $\mathrm{P}=0.4258$ & $7(3.2 \%)$ \\
\hline
\end{tabular}

The use of new technological approaches, including cytoprotective treatment of bleeding defects with biologically active draining sorbents of a new generation in combination with local hemostatics in the complex therapy of patients with ulcerative GDB, has significantly improved the results of treatment, which is confirmed by high rates of final hemostasis $(95.0 \%)$, indicators of the effectiveness of primary EH in type FIA-IB (93.1\%) and prevention of recurrence of FIIA-IIB bleeding $(92.5 \%)$, with a low frequency of repeated bleeding $(4.07 \%)$, emergency surgeries $(2.7 \%)$, and mortality (3.2\%). 


\section{Conclusion}

Currently, in the structure of ulcerative gastroduodenal bleeding, acute symptomatic gastroduodenal ulcers are the most common $-64.7 \%$, and the share of peptic ulcer disease complicated by bleeding accounts for $35.3 \%$ of cases only. Peptic ulcer disease and gastroduodenal ulcers complicated by bleeding have certain clinical and epidemiological features, which must be taken into account when treating these patients. The use of modern, new technological approaches based on the introduction of innovative endoscopic technologies with the use of biologically active draining sorbents and local hemostatic agents allowed us to improve the results of treatment, to ensure the possibility of final hemostasis in $95.0 \%$ of cases, to reduce the number of recurrent hemorrhages to $4.07 \%$ of cases and total mortality to $3.2 \%$. Symptomatic gastroduodenal ulcers are more difficult to treat, which shows the need to develop new complex technologies for their treatment.

\section{Sources of Funding}

This work was partially supported by the Council on Grants of the President of the Russian Federation for State Support of Young Scientists and Leading Scientific Schools (Grant MK-1069.2020.7).

\section{Competing Interests} interests.

The authors declare that they have no competing

\section{References}

1. Cherednikov EF, Barannikov SV, Yuzefovich IS, Polubkova GV, Maleev YuV, Volkova IV, Vysotskaya AT, Strygin OV, Ovsyannikov ES. Innovative Endoscopic Technologies in the Complex Treatment of Patients with Unstable Stopped Gastroduodenal Bleeding. International Journal of Biomedicine. 2021;11(1):24-28. doi:10.21103/ Article11(1)_OA4

2. Cherednikov EF, Barannikov SV, Maleev YuV, Fursov KO, Litovkina TE, Zakurdaev EI, Ovsyannikov ES. Experimental justification of using Aseptisorb-A and platelet-rich plasma in endoscopic treatment of mold bleeding stomach defects. International journal of biomedicine. 2017;7(4):298-301. doi: 10.21103/Article7(4)_OA5

3. Cherednikov EF, Barannikov SV, Zhdanov AI, Moshurov IP, Polubkova GV, Maleev YuV, Ovsyannikov ES, Myachina DS. Combimed Use of Biologically Active Hemostatic and Granulated Sorbent in Endoscopic Cytoprotective Hemostasis in Patients with Bleeding Gastroduodenal Ulcers. International Journal of Biomedicine. 2020;10(2):129-132. doi: 10.21103/ Article10(2) OA8

4. Cherednikov EF, Maleev YuV, Chernyh AV, Litovkina TE, Bondarenko AA, Cherednikov EE, Popov AV. [Current views on the diagnosis, treatment, and prevention of ruptured hemorrhagic syndrome (Mallory-Weiss syndrome)]. Journal of New Medical Technologies. 2016;23(4):161-172. [Article in Russian].
5. Cherednikov E F, Chernyh AV, Maleev YuV, Popov AV, Stekolnikov VV. [Topographical and anatomical prerequisites for the development of Mallory-Weiss syndrome]. Bulletin of the Russian Military Medical Academy.2015;(S2):153-154. [Article in Russian].

6. Cherednikov EF, Batkaev AR, Baev VE. [The Reparative regeneration of erosive-ulcerative lesions of the stomach and duodenum in the local treatment of hydrophilic granular sorbents]. System Analysis and Management in Biomedical Systems. 2005;4(2):224-225. [Article in Russian].

7. Shapkin YG, Potahin SN. [The dynamics of main indicators for the treatment of ulcerative gastroduodenal bleeding - the analysis of several years studies]. Saratov Journal of Scientific Research. 2014;10(3):456-460. [Article in Russian].

8. Cherednikov EF, Deryaeva OG, Adianov VV, Ovchinnikov IF, Popov AV. [Modern directions of prevention and treatment of patients with gastrointestinal bleeding in the center]. System Analysis and Management in Biomedical Systems. 2014; 13(2):426-433. [Article in Russian].

9. Barannikov SV, Cherednikov EF, Polubkova GV, Vysotskaya AT, Shkurina IA. [Modern aspects of epidemiology of bleeding from gastroduodenal ulcers (based on the materials of the Voronezh specialized Center)]. Preventive medicine. 2020;23(5-2):10. [Article in Russian].

10. Cherednikov EF, Glukhov AA, Romantsov MN, Maleev YuV, Barannikov SV, Shkurina IA, Vysotskaya AT, Ovsyannikov ES. Hemostatic Agents in Combination with Diovine for Local Treatment of Simulated Bleeding Gastric Ulcers. International Journal of Biomedicine. 2020;10(2):138141. doi: 10.21103/Article10(2)_OA10

11. Budnevsky AV, Cherednikov EF, Popov AV, Ovsyannikov ES, Kravchenko AY, Fursov KO. A Complex Multidisciplinary Approach to Prevention Gastro-duodenal Bleeding in Patients of General Hospital. International Journal of Biomedicine. 2017;7(3):204-207. doi: 10.21103/ Article7(3)_OA8

12. Cherednikov EF., Budnevsky AV, Popov AV, Fursov KO. A new opinion on gastroduodenal bleeding preventon in patients with somatic patology. The EPMA Journal. 2017; 8(S1): 46.

13. Starkov YG, Domarev LV, Sitnikov EA, Russkikh AE, Svitina KA. [Characteristics and effectiveness of various methods of endoscopic hemostasis in ulcerative bleeding]. Surgery in Gastroenterology. 2014;6:34-37. [Article in Russian].

14. Cherednikov EF, Maleev YuV, Chernyh AV, Litovkina TE, Cherednikov EE, Shevtsov AN. [Modern views on the etiology and pathogenesis of ruptured hemorrhagic syndrome (Mallory-Weiss syndrome)]. Journal of anatomy and Histopathology. 2016;5(1):86-98. [Article in Russian].

15. Adianov VV, Cherednikov EF. [Optimizing treatment of gastroduodenal bleeding in patients with high surgical risk]. System Analysis and Management in Biomedical Systems. 2014; 13(4): 841-846. [Article in Russian].

16. Cherednikov EF, Yuzefovich IS, Maleev YuV, Barannikov SV, Litovkina TE, Polubkova GV, Ovsyannikov ES. The

*Corresponding author: Evgeniy S. Ovsyannikov, PhD, ScD. Department of faculty therapy, Voronezh State Medical University named after N.N. Burdenko. Voronezh, Russia. E-mail: ovses@ yandex.ru 
Use of the Hemostatic Agent Zhelplastan in Combination with a Granulated Sorbent in the Treatment of Patients with MalloryWeiss Syndrome. International Journal of Biomedicine. 2021;11(2):160-163. doi:10.21103/Article11(2)_OA7

17. Cherednikov EF, Kashurnikova MA, Romantsov MN, Barannikov SV, Bolkhovitinov A E, Gaponenkov DG, Lyubimov PYu. [Experimental study of new means of local hemostasis in the treatment of ulcerative bleeding]. Scientific and Medical Bulletin of the Central Chernozem Region. 2016;(65):27-33. [Article in Russian].

18. Cherednikov EF, Barannikov SV, Romantsov MN, Popov AV. New aspects of preventive endoscopic hemostasis in the treatment of peptic ulcer bleeding in the experimental condition. The EPMA Journal. 2017;8(S1):45.

19. Romantsov MN, Cherednikov E F, Danilenko VI, Stepanov DS, Fursov K O, Deryaeva AG. [Morphological Characteristics of Processes of Simulated Bleeding Gastric Defects Reparation in Treatment with Gelplastan and Diovin]. Journal of Anatomy and Histopathology. 2017;6(1):81-86. [Article in Russian].
20. Cherednikov EF, Barannikov SV, Fursov KO, Polubkova GV, Danilenko VI, Stepanov DS. [Healing of bleeding experimental defects of the stomach with topical anilovin and platelet-rich plasma]. Journal of Volgograd State Medical University. 2017; 2(62): 130-133. [Article in Russian].

21. Forrest JA, Finlayson ND, Shearman DJ. Endoscopy in gastrointestinal bleeding. Lancet. 1974 Aug 17;2(7877):3947. doi: 10.1016/s0140-6736(74)91770-x. PMID: 4136718

22. Gorbashko AI. Diagnostics and treatment of blood loss. Moscow: Meditsina. 1982:224 pp. [In Russian].

23. Cherednikov EF, Romantsov MN, Ovchinnikov IF, Glukhov AA, Adianov VA, Vysotskaya AT; Voronezh State Medical University named after N. N. Burdenko [Method of endoscopic treatment of ulcerative gastroduodenal bleeding]. Patent for Invention RUS No. №2633588. Application No. 2015147321 dated 03.11.15; publ. 10.05.2017; Bulletin No. 13. [In Russian].

24. Ulcerative gastroduodenal bleeding. National clinical guidelines. Hirurgicheskaja Praktika. 2015;2:62-64. [In Russian]. 